\title{
Counting carbon or counting coal? Anchoring climate governance in fossil fuel-based accountability frameworks
}

Fergus Green and Declan Kuch

August 2021

Centre for Climate Change Economics and Policy Working Paper No. 396

ISSN 2515-5709 (Online)

Grantham Research Institute on Climate Change and the Environment Working Paper No. 368

ISSN 2515-5717 (Online) 
The Centre for Climate Change Economics and Policy (CCCEP) was established by the University of Leeds and the London School of Economics and Political Science in 2008 to advance public and private action on climate change through innovative, rigorous research. The Centre is funded by the UK Economic and Social Research Council. Its third phase started in October 2018 with seven projects:

1. Low-carbon, climate-resilient cities

2. Sustainable infrastructure finance

3. Low-carbon industrial strategies in challenging contexts

4. Integrating climate and development policies for 'climate compatible development'

5. Competitiveness in the low-carbon economy

6. Incentives for behaviour change

7. Climate information for adaptation

More information about CCCEP is available at www.cccep.ac.uk

The Grantham Research Institute on Climate Change and the Environment was established by the London School of Economics and Political Science in 2008 to bring together international expertise on economics, finance, geography, the environment, international development and political economy to create a world-leading centre for policy-relevant research and training. The Institute is funded by the Grantham Foundation for the Protection of the Environment and a number of other sources. It has 12 broad research areas:
1. Biodiversity
2. Climate change adaptation and resilience
3. Climate change governance, legislation and litigation
4. Environmental behaviour
5. Environmental economic theory
6. Environmental policy evaluation
7. International climate politics
8. Science and impacts of climate change
9. Sustainable finance
10. Sustainable natural resources
11. Transition to zero emissions growth
12. UK national and local climate policies

More information about the Grantham Research Institute is available at www.Ise.ac.uk/Granthamlnstitute

\section{Suggested citation:}

Green F and Kuch D (2021) Counting carbon or counting coal? Anchoring climate governance in fossil fuel-based accountability frameworks. Centre for Climate Change Economics and Policy Working Paper 396/Grantham Research Institute on Climate Change and the Environment Working Paper 368. London: London School of Economics and Political Science 


\title{
COUnTING CARbon OR COUNTING COAL? Anchoring Climate Governance in Fossil Fuel-BASED ACCOUNTABILITY FRAMEWORKS
}

\author{
Fergus Green $^{\mathrm{a}, \mathrm{b}}$ and Declan Kuch ${ }^{\mathrm{c}}$ \\ a Grantham Research Institute on Climate Change and the Environment, London School of Economics \\ and Political Science [until 31 August 2021]; ${ }^{\text {b }}$ Department of Political Science and School of Public \\ Policy, University College London [from 1 September 2021]; \\ c Institute for Culture and Society, Western Sydney University \\ Correspondence: fergus.green@ucl.ac.uk
}

\begin{abstract}
For decades, the object of international climate governance has been greenhouse gases, standardised to tonnes of carbon dioxide-equivalent. The ongoing inadequacy of decarbonisation efforts based on this system have prompted calls to expand the scope of international climate governance to include restrictions on the supply of fossil fuels. Such initiatives could rely on accountability frameworks based on fossil fuel reserves, production, or infrastructure, yet to date there has been little consideration of the different implications for climate governance of each of these options. We seek to inform such discussions by undertaking a sociotechnical analysis of various existing schemes for the monitoring, reporting and verification of fossil fuels. We identify serious risks from anchoring climate governance in fossil fuel reserves: the extensive role for expert judgement that enters into the construction of reserves figures, and the exclusive control of reserves evaluation and classification practices by profit-motivated firms in the fossil fuel industry, raise serious risks of "gaming"; moreover, the fact that reserves figures are in part a function of climate governance outcomes means reserve-based climate governance would face an endogeneity problem. More promising directions for supply-side climate governance, we find, lie in accountability frameworks based on a combination of fossil fuel production volumes and infrastructure, since infrastructure and production-related transactions are more transparent to a wider range of actors. Crucially, this transparency would provide much-needed opportunities for democratic oversight of the data underpinning climate governance efforts, opening up new channels for holding states to account for their climate performance.
\end{abstract}

Acknowledgements: The authors are grateful to Murat Arsel, Harro van Asselt, Rebecca Byrnes, Federico Mor, Lorenzo Pellegrini, Rob Schuwerk and Johnny West for helpful comments, and to Lachlan Clancy for helpful discussion. Fergus Green acknowledges support from the Grantham Foundation for the Protection of the Environment and the ESRC through the Centre for Climate Change Economics and Policy. Declan Kuch acknowledges support from the Australian Renewable Energy Agency. 


\section{Introduction}

International climate governance has historically been anchored in a carbon-based accountability framework. The objects of governance under this framework are territorial, anthropogenic point sources of greenhouse gas emissions and removals by sinks, standardised to tonnes of carbon dioxide-equivalent $\left(\mathrm{CO}_{2} \mathrm{e}\right)$ (Dehm 2018). State responsibility is conceptualised in terms of limiting or reducing $\mathrm{CO}_{2} \mathrm{e}$, and information about states' performance is generated via systems for the measurement/monitoring, reporting and verification (MRV) of greenhouse gas emissions and removals. While state responsibility for net territorial greenhouse gas emissions remains a broadly accepted climate governance norm, experience with actually existing carbon-based MRV systems has led many to question whether carbon-based accountability frameworks are conducive to just and effective climate mitigation in the public interest. ${ }^{1}$

At the same time, many scholars, activists and policymakers have sought to direct attention upstream, calling for international climate initiatives structured around measures to restrain and reduce the supply of fossil fuels (Asheim et al. 2019; Collier and Venables 2015; Green 2018b; Green and Denniss 2018; Newell and Simms 2020; Piggot et al. 2018). We argue that if this cooperation is to eventuate, a fossil fuel-based accountability framework is needed-one in which state responsibility and associated MRV systems become focused on a new object of governance, namely fossil fuel reserves, production, or infrastructure. But which of these objects is most conducive to just and effective supply-side climate governance?

To date, there has been little research on the potential of these alternative fossil fuel-based accountability frameworks to contribute to climate governance. A handful of studies in the last decade broke important ground by considering the merits and drawbacks for climate governance of allocating state responsibility for climate change on the basis of fossil fuel extraction (Davis, Peters, and Caldeira 2011; Harrison 2015; Kerr and Duscha 2014;

Steininger et al. 2016). Yet, to our knowledge, no studies have evaluated the prospects for fossil fuel-based accountability frameworks in international climate governance with reference to actually existing fossil fuel MRV systems. Since the most insightful critiques of carbon-based accountability frameworks have been developed through rigorous analysis of actually existing carbon-based MRV systems, we believe that the nascent discussions of fossil fuel-based accountability frameworks could usefully be informed by consideration of how fossil fuel MRV systems work in practice. Thus, rather than starting with the goal of climate mitigation and assuming that the object of governance should be the most proximate means of reaching the goal, our inquiry begins with the potential objects of governance themselves, considering what prospects each object offers the would-be climate governance architect.

Fossil fuels are already accounted for by market and state actors, primarily for the purposes of securing and transacting supplies. However, no comprehensive, global accountability framework for fossil fuels currently exists for any purpose, let alone for the purpose of climate governance. Drawing on theories and tools from Science \& Technology Studies, we

\footnotetext{
${ }^{1}$ See below section entitled "The limits of carbon-based accountability frameworks".
} 
analyse examples of these accountability frameworks to illuminate the social, technical and political processes by which relevant facts about fossil fuels have been produced and mobilised for particular economic and political purposes (Jasanoff 2006). Do these frameworks lend themselves to forms of elite-driven governance similar to carbon-based frameworks, or do they provide opportunities for expanded democratic oversight? And what does this imply for the prospects for just and effective climate governance?

The article is structured as follows. We first specify what we mean by accountability frameworks and explain why they matter for governance in general, and for international climate cooperation in particular. We then summarise the main critiques of carbon-based accountability frameworks, with an emphasis on sociological literature that has engaged with actually existing MRV systems. Subsequently, we analyse and discuss three types of fossil fuel-based MRV systems, each based on a different object of governance: fossil fuel reserves, production, and infrastructure. We conclude with a comparative discussion that summarises the contributions of the paper and the implications of our findings for international climate governance.

\section{Accountability frameworks and climate governance}

We conceptualise an accountability framework, in the context of international climate governance, as consisting of the following three elements: (i) a set of norms by which responsibility for achieving collective goals is allocated among agents (we assume responsibility will pertain to an object of governance that is instrumental to, or a proxy for, the ultimate goal); (ii) a system of MRV so as to yield factual information about agents' causal role with respect to the relevant object of governance; and (iii) a set of institutions or practices for holding agents to account for their (non-)compliance with the relevant norms. ${ }^{2}$

With regard to element (i), we assume for the purpose of our analysis that parties are ultimately interested in achieving the goal of just and effective climate mitigation, and that some form of fossil fuel-based state responsibility is normatively appropriate. ${ }^{3} \mathrm{We}$ are interested in investigating which particular fossil fuel-based objects of governance are more or less conducive to this goal. For this purpose, we shall focus on element (ii), namely MRV systems for the various objects we consider. The core function of an MRV system is to yield factual information about whether collective goals are being achieved and about which agents have causally contributed to the achievement, or otherwise, of those goals. Ideally, this information is of high quality - i.e. transparent (observable to third parties), accurate (a true representation), comparable (able to be meaningfully compared across entities) and timely (available in close to real-time). ${ }^{4}$ Together, the first two elements of an accountability

\footnotetext{
${ }^{2}$ For a similar scheme, albeit further disaggregated into five categories, see Gupta and van Asselt (2019).

${ }^{3}$ For discussion of this element, see Harrison (2015) and Steininger et al. (2016).

${ }^{4}$ This formulation is a slight modification of the UNFCCC's criteria for national accounting: transparent, accurate, complete, comparable, consistent. We drop "complete" and "consistent" as these are less relevant outside of UNFCCC-specific carbon accounting schemes, and add "timely" because the timeliness of data availability clearly matters if states are to be held accountable in ways that are conducive to improved climate outcomes.
} 
framework reveal which agents have (not) complied with their responsibilities. Accordingly, they provide the normative and factual basis for holding the relevant agents to account.

This brings us to element (iii), which concerns the institutions or practices by which a relevant agent is held to account (Gupta and van Asselt 2019; Newell 2008). Some international regimes include formal compliance systems. High quality information is a prerequisite for holding agents accountable through such systems where they exist. However, we assume that formal compliance systems under the international climate regime will for the foreseeable future remain soft, under-resourced, and largely ineffective in advancing decarbonisation (Karlsson-Vinkhuyzen et al. 2018). Crucially, though, they are not the only channels through which states can be held to account.

Numerous alternative accountability channels exist, and these are critically important to the success of global climate governance (van Asselt 2016; Falkner 2016; Hale 2016; Jacobs 2016; Karlsson-Vinkhuyzen et al. 2018; Keohane and Oppenheimer 2016). ${ }^{5}$ We emphasise two such channels: (i) at the international level, informal assessments by states of their peers' compliance with an international norm, which inform their behaviour toward the (non)compliant state; and (ii) domestically and transnationally, various forms of "civil redress" by civil society actors, such as NGO and media criticism, protests and civil disobedience (Mason 2005; see also Newell 2008).

The importance of MRV systems for climate governance can thus be (re-)conceptualised in terms of their role in enabling a variety of agents to hold states to account through alternative accountability channels. These actors may be able to impose various kinds of costs on noncompliant states, be they economic costs or social/political costs such as reputational damage, blame, disesteem, and exclusion from international fora. Avoiding these various costs (or seeking benefits from compliance) is a key reason why states are more likely to unilaterally comply with international agreements when they know that compliance can easily be verified by third parties (Chayes and Chayes 1991, 323-24, 1998).

Crucially, however, different types of agents may have different motivations and different means available to impose costs (or confer benefits) on states. Elite actors (within other states, national governments, and business firms) may have greater means to impose cost on non-compliant governments, yet their interests are more likely to be entangled with those of the non-compliant state. This risk is especially great in the context of climate change, given the close relationships that typically exist between the state, the energy sector, energyintensive industrial interests and finance capital (Paterson and Newell 2010). Accordingly, a democratisation of the information needed to hold states to account is likely to be conducive to just and effective climate governance (Stevenson 2021). This imperative illuminates the value for climate governance of MRV systems that yield high quality information about state compliance that is transparent to civil society actors.

Because it affects states' compliance rates, the quality of information produced by an MRV system - including its transparency to a wide range of actors - can also have dynamic effects

\footnotetext{
${ }^{5}$ Mason makes a similar point in relation to global environmental governance more generally (Mason $2008,10)$.
} 
on international cooperation. First, as more states comply and see others complying, the social costs of non-compliance increase (Collier and Venables 2015; Finnemore and Sikkink 1998; Johnston 2001). Modest improvements in verifiable compliance can thus trigger tipping dynamics that result in relatively rapid increases in overall regime compliance-a phenomenon often interpreted as a strengthening of the underlying social/moral norm (Finnemore and Sikkink 1998; Green 2018a; Nyborg et al. 2016). Second, increased compliance, where mutually verified, can facilitate greater stringency in collectively agreed international rules over time by building trust and confidence among cooperating parties (Bell et al. 2012; Chayes and Chayes 1998; Victor 2011).

In sum: the chosen object of governance influences the prospects for MRV, and hence the quality of information available to different kinds of actors; this, in turn, influences the potential for different actors to hold governments to account via various alternative accountability channels; these accountability channels ultimately influence state compliance and the prospects for enhancing cooperation over time. With this theoretical model in mind, we now summarise the state of knowledge about carbon-based accountability frameworks, before considering the prospects for fossil fuel-based frameworks.

\section{The limits of carbon-based accountability frameworks}

Carbon accounts expressed in terms of $\mathrm{CO}_{2} \mathrm{e}$, though presented by scientists and many governing actors as determinate facts, involve multiple layers of abstraction from the underlying physical reality of emissions and the multiplicity of social contexts in which they are produced (Dehm 2018; Lövbrand and Stripple 2011). "Greenhouse gas" is an umbrella term for a basket of gases with different chemical properties, each of which has a different warming effect. They are rendered equivalent to one another via the notion of Global Warming Potential, which enables all gases to be standardised against the warming effect of carbon dioxide over a 100-year timeframe (hence ' $\mathrm{CO}_{2} \mathrm{e}^{\prime}$ ), albeit with considerable uncertainty and requiring fundamental value judgements. ${ }^{6}$ These gases are primarily produced from the combustion of fossil fuels to produce energy, but also from a range of industrial and agricultural processes. Greenhouse gases are also sequestered in and released from the land-sector in natural processes and as a result of human activities. These various causal processes, moreover, are embedded in diverse sociotechnical, economic and political contexts. By abstracting from these contextual features in order to isolate common properties, carbon accounting proponents created equivalences between diverse activities (Dehm 2018; Lövbrand and Stripple 2011; MacKenzie 2009).

The historical dominance of $\mathrm{CO}_{2} \mathrm{e}$ as the object of climate governance has been underpinned by its support within multiple constituencies for whom these layers of abstraction have served useful functions. On the one hand, scientists, economists, policymakers and professionalised environmental NGOs have supported carbon-based accountability because it is widely perceived to hold out the promise of human control over the climate system through a kind of precision management of all of its human-controlled inputs (Allan 2017; Victor 2001). At the same time, however, carbon-based accountability has been supported by

\footnotetext{
${ }^{6}$ This has been particularly controversial with regard to methane (see Dehm 2018, 313).
} 
carbon-intensive states and firms because the fungibility enabled by abstraction has provided opportunities for them to maximise flexibility and minimise compliance costs: path-dependent fossil fuel-based systems have been allowed to expand while carbon-based obligations have been met through less scrutable and more tenuous mitigation activities such as land-based sequestration, industrial gas destruction, "offsetting" and avoided deforestation (Dehm 2018; Kuch 2015).

These outcomes have been facilitated by the complexity of carbon-based MRV systems, especially in the areas just mentioned. This complexity necessitates heavy reliance on professional experts - to establish baselines, develop monitoring systems, set reporting and other standards, formulate procedures for making disclosures, interpret such disclosures, and evaluate their performance (Kuch 2015; MacKenzie 2009). These acts have political significance and affect large financial flows in the nascent carbon economy, meaning carbon professionals exercise de facto political authority (Kuch 2015; Lövbrand and Stripple 2011; Pearse 2018; Stripple and Lövbrand 2010). It therefore matters what incentives these professionals face, and whose interests they serve. To a considerable extent, carbon management expertise has been employed by those agents with the greatest interest in minimising their apparent causal role in driving climate change (Kuch 2015). Carbonintensive states employ these experts to help them shape international MRV and accounting systems in ways that maximise their flexibility (Kuch 2015). Meanwhile, the fact that anthropogenic greenhouse gas point sources are highly dispersed and mostly controlled by private agents means domestic regulatory systems inevitably devolve extensive authority over MRV processes to carbon-intensive firms and for-profit auditing firms (see Bellassen and Stephan 2015). In these circumstances, there is a risk that the subjective judgements of these experts become biased toward the narrow interests of their employers and clients. Decades of experience with real-world carbon-based MRV systems has revealed how easily this form of corruption can occur: systems of carbon accounting, trading and offsetting have created vast opportunities for mischief by states and firms, ranging from system-gaming to outright fraud (Bellassen et al. 2015; Interpol 2013; Kuch 2015; Martin and Walters 2013; Schneider 2009, 2011; Shishlov, Morel, and Bellassen 2016).

The problems with carbon-based accountability frameworks have undoubtedly undermined climate governance efforts under the auspices of the UNFCCC. The vast scope for gaming in carbon accounting processes makes it easy for states to present themselves as taking meaningful action whilst in fact doing little to address the systemic drivers of GHG emissions (Kuch 2015; Shishlov, Morel, and Bellassen 2016; Stevenson 2021). The resulting epistemic murkiness does not appear to have built trust and confidence among participating states or resulted in increased ambition (Gupta and van Asselt 2019). ${ }^{7}$ With the Paris Agreement's more decentralised, voluntary and heterogeneous approach to mitigation, the

\footnotetext{
${ }^{7}$ At the very least, mistrust over carbon-based accountability appears to have undermined progress in implementing article 6 of the Paris Agreement concerning "market mechanisms" (Blum 2020; Streck 2020).
} 
pursuit of accountability for carbon fluxes has only become more elusive (Keohane and Oppenheimer 2016; Weikmans, van Asselt, and Roberts 2020).

Carbon-based accountability frameworks, in short, have well served the narrow interests of carbon-intensive states and firms, financial actors, and the expert community of carbon managers. Yet they have not simultaneously delivered the precision management system for climate control for which its more public-spirited advocates have long hoped. These outcomes have led many to question whether carbon-based accountability frameworksand the opaque, elite-dominated forms of governance they enable-really serve the public interest, understood in terms of just and effective climate mitigation (Kuch 2015; Pearse and Böhm 2014). It is in this context that the search for accountability frameworks anchored in fossil fuels has emerged.

\section{Fossil fuel-based accountability frameworks}

\section{Fossil fuel reserves}

Fossil fuel reserves are measures that relate to physical stocks of oil, gas and coal under the Earth's surface. However, they are not bounded, factual quantities. Rather, reserves are sociotechnical constructs that combine probabilistic expert judgements about the existence of geological resources with judgements about the commercial viability of those resources (Association of Chartered Certified Accountants and Carbon Tracker Initiative 2013; Bebbington et al. 2020).

In jurisdictions in which privately-owned mining and petroleum firms predominate, industry standards for evaluating and classifying reserves were developed at national levels to foster investor confidence in fossil fuel firms and to satisfy regulatory interests in market stability (Camisani-Calzolari 2004). Consistent with wider trends in standardisation noted by sociologists (Timmermans and Epstein 2010), these standards were later internationalised to meet the needs of globalising financial capital and fossil fuel markets, and in some cases to allay security concerns and satisfy international agencies (e.g. the International Atomic Energy Agency with respect to Uranium) (Camisani-Calzolari 2004). A commonly used template for evaluating and classifying mineral reserves is that published by the Committee for Mineral Reserves International Reporting Standards (CRIRSCO) under the auspices of a CEO-led industry body, the International Council for Mining and Metals. The equivalent template for petroleum reserves is the Petroleum Resource Management System (PRMS) developed by the Society of Petroleum Engineers. ${ }^{8}$ Many national stock exchanges and regulatory bodies adopt evaluation and classification standards that map onto the CRIRSCO and PRMS templates (Bebbington et al. 2020).

According to classification schemes standardly used in both the mining and petroleum industries, reserves "refers to oil and gas and mineral resources that are commercially viable", and they are "further broken down into the sub-categories of proved (1P), probable $(2 \mathrm{P})$ and possible $(3 \mathrm{P})$ ", reflecting increasing uncertainties as to their geological status and

\footnotetext{
${ }^{8}$ PRMS-2018 Update, <https://www.spe.org/en/industry/petroleum-resources-management-system$\underline{2018 />}$.
} 
commercial viability (ibid, p.8). Resources refers to resources that have been discovered, but have not been evaluated to be commercially viable because of any one of a number of contingencies (e.g. economic, legal, environmental, social and governmental). Consider, for example, the classification scheme for mineral reserves produced by CRIRSCO, shown in Figure 1. Under the CRIRSCO scheme, the non-geological contingencies that determine whether resources can be classified as reserves are known as "modifying factors", and a probabilistic assessment of these factors is a key part of the classification process.

Figure 1: Mineral resource classification scheme (CRIRSCO)

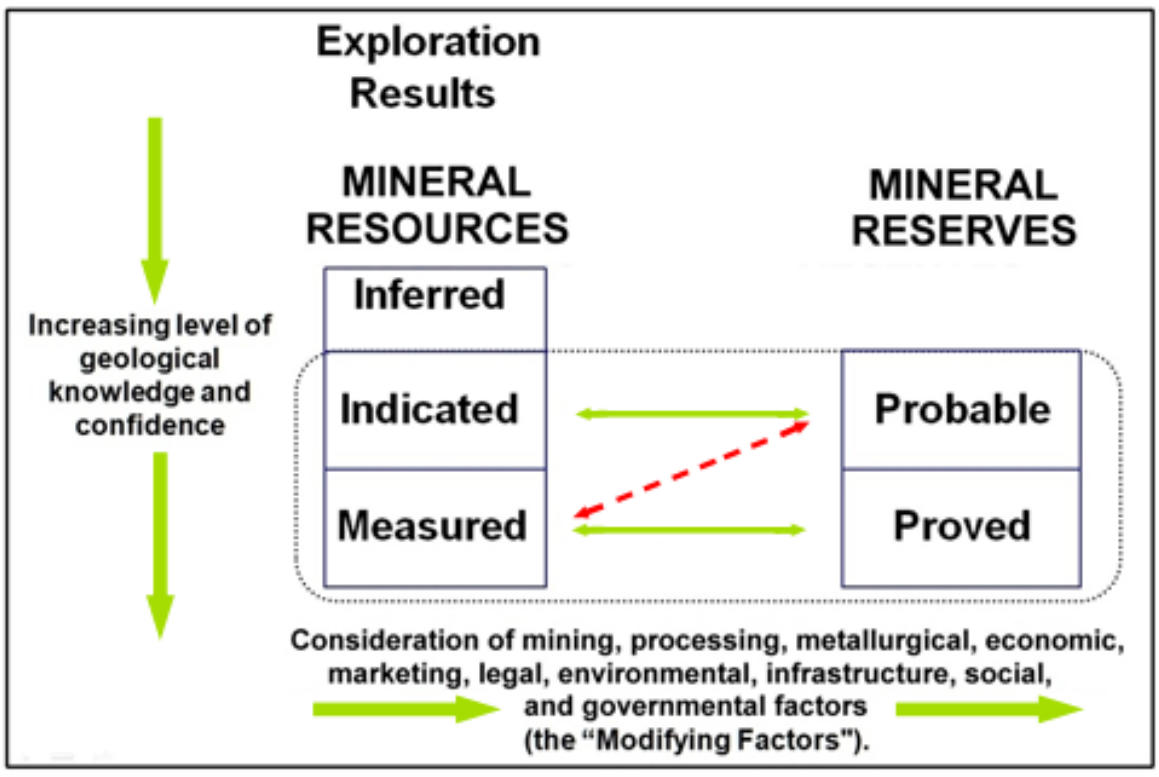

Source: CRIRSCO, "About CRIRSCO", <http://www.crirsco.com/background.asp>.

Clearly, fossil fuel reserves are highly abstracted quantities. They are a function of both geological and commercial assessments and they are thoroughly entangled with processes of marketisation and regulation (Barry 2013; Huber 2013; Mitchell 2011). Moreover, their construction relies extensively on professional judgement. This is so, for example, even at the point of the initial oil pumped from a newly commercialized exploration well-known in the industry as 'first oil'. In Weszkalnys' (2015) analysis of 'first oil', "oil is both a measure of value in a globalized economy and a geologic matter that can defy precision prior to, and even during, its extraction" (ibid., p. 614). Thus, the Society for Petroleum Engineers heralds the importance of their members' professional skills in evaluating and classifying petroleum reserves: "Reserves derived under these definitions rely on the integrity, skill, and judgment of the evaluator." ${ }^{9}$ Reserves figures attain their status as financial fact by relying on professional bodies who circumscribe the terms of those qualified to interpret geological data and inform investors. Across the various schemes this professional is standardly

\footnotetext{
${ }^{9}$ Petroleum Reserves Definitions [1997 Archive], $<$ https://www.spe.org/en/industry/petroleumreserves-definitions/>.
} 
referred to as the 'Competent Person', who must be a member of a professional body and possess certain specified experience. ${ }^{10}$

These features of reserves give rise to three concerns about the suitability of reserves as an object of climate governance.

The first concern pertains to the hybrid geological-commercial nature of reserves and the extensive reliance on expert judgement in constructing reserves figures. As discussed, to count a quantity of fossil fuels as "reserves", the evaluator needs to have confidence not only in the quantity of the resources in place, but also in the commercial exploitability of those resources, which is contingent on various technological, economic, infrastructural, legal, political and other factors. Probabilistic judgements about these factors are subject to a range of political and technical contingencies (Weszkalnys 2015) - a feature that is compounded by the multifactorial nature of the reserves classification process. Should reserves come to be the object of supply-side climate governance, the contingency of reserves figures on subjective judgements about these contingent factors would leave extensive room for manipulation and gaming. ${ }^{11}$

The risk of gaming is amplified by a second concern: the evaluation and classification of a mining and petroleum firm's reserves is an elite process controlled by a small epistemic community with vested interests in expanded production for commercial gain. This concern is particularly acute in countries with nationally-owned fossil fuel producers, such as the national oil companies (NOCs) that control an estimated 90\% of global oil reserves (Tordo, Tracy, and Arfaa 2011). Evaluation and classification practices in unlisted, state-owned fossil fuel firms are controlled by the firms themselves, and, like many decisions by such firms, tend to be opaque to third parties other than relevant commercial partners (Manley and Heller 2021). ${ }^{12}$ Unlisted privately-owned firms, too, often face few public checks on their self-determination of reserves. Stock-exchange listed firms are subjected to additional regulatory requirements governing the disclosure of reserves for purposes such as their initial public offering and annual reporting. Regulations governing listed firms typically cross-refer to applicable industry standards for reserves evaluation and classification, which require reserves to be evaluated by "Competent Persons", as discussed above (Association of Chartered Certified Accountants and Carbon Tracker Initiative 2013). However, only in some cases are Competent Persons required to be independent of the firm that owns the resource. Even where independent experts are engaged, the evaluation and classification

\footnotetext{
${ }^{10}$ CRIRSCO reporting template, 2019,

$<$ http://www.crirsco.com/templates/CRIRSCO International Reporting Template November 2019.p $\underline{\mathrm{df}>}$ and PRMS-2018 Update, < $<$ ttps://www.spe.org/en/industry/petroleum-resources-managementsystem-2018/>.

${ }^{11}$ It may be that, in practice, evaluators confine their judgements primarily to geological matters. To the extent this is the case, however, reserves figures are a less reliable approximation of a firm's or state's contribution to climate change, since these reserves may have a low probability of commercial exploitation. In any event, the potential for gaming that we highlight here would remain.

${ }^{12}$ Lax domestic regulation in many NOC jurisdictions also leaves NOCs with little incentive to disclose their reserves other than international pressure, which many NOCs and their governments have long resisted (Heller and Mihalyi 2019).
} 
process itself remains the province of firms and professionals with a narrow band of expertise and motivated by profit. Like the accounting firms that audit corporate books and verify carbon offsets, independent reserves evaluators have an interest in expanding the market for their services, keeping clients happy and growing their client base. Their clients, moreover, are fossil fuel producers - an industry notorious for climate obstructionism and regulatory evasion. ${ }^{13}$

The third concern with using reserves as an object of climate governance pertains to the fact that fossil fuel reserves - fundamentally a firm-level construct-are a part function of macrolevel phenomena like climate governance. As we have seen, to be classified as reserves, an evaluator must have high confidence in the presence of various contingent factors that go to commercial exploitability, including the firm's capacity to extract the resources lawfully and profitably. Climate governance-if it is to be effective-requires states to pass laws that either directly limit the amount of fossil fuels that firms can extract, or that indirectly do so by reducing demand for, and hence the profitability of, extracted fossil fuels. This gives rise to an endogeneity problem: if reserves are to form the basis for holding states to account for their contributions to climate change with a view to ratcheting up climate action, then the very changes in climate laws that reserves-based climate governance would be supposed to precipitate would themselves alter the reserves figures. Because reserves reflect firmmediated expectations about laws, costs of production, demand scenarios and prices, any serious decarbonisation process would likely trigger significant fluctuations in reserves classifications and disclosures. Under these conditions, international climate governance anchored in reserves-based accountability would become akin to shadow boxing.

\section{Fossil fuel production}

Fossil fuel production figures refer to the actual, physical quantities of oil, gas and coal that are extracted from the ground and commercially supplied (or directly used in the producing firm's operations) over a given time period. The physical quantities can be measured in various ways - primarily by volume, weight or energy content-depending on the fuel in question, its physical state, and the purpose of the measurement. For example, petroleum is often quantified volumetrically (e.g. barrels of oil; cubic metres of gas) by firms for commercial purposes, such as contracts and purchase orders, and for compliance purposes, such as reporting to capital markets, tax authorities and regulatory agencies, whereas it is measured by weight for purposes of shipping. ${ }^{14}$ Coal is standardly measured in tonnes for these purposes. Since commercial buyers of fossil fuels are typically interested in the amount of energy that can be produced from the fuels, measures of a fuel's density are typically also used for commercial purposes. A fuel's energy content affects its "quality", along with other factors such as the presence of impurities in the fuel.

\footnotetext{
${ }^{13}$ See, e.g., National Whistleblower Centre, Oil \& Gas Case Studies, $<$ https://www.whistleblowers.org/oil-gas-case-studies/>. This malfeasance extends to fraudulent reserves classification and reporting, as illustrated by the Shell oil and gas reserves scandal of the mid-2000s (see Taylor 2006).

${ }^{14}$ Fossil gas can be liquefied for transport via LNG tanker.
} 
Weight and volume can be readily ascertained by any agent who has physical access to the relevant stock of fuel and to standard instruments for weighing and metering industrial quantities of it. On the one hand, this means that produced fossil fuel volumes and tonnages are the exclusive domain of the production firm, its customers, and the shipping, pipeline, or other transportation operator (if contracted to a third party), which limits the scope for civil society oversight. On the other hand, these other commercial parties have an interest in the accurate measurement of volumes and weights so as to ensure they are getting what they paid for, and the amounts can be verified using standard instrumentation. This both limits the scope for subjective judgement and allows for a degree of triangulation among different parties to a transaction, ultimately constraining the scope for data manipulation. The ready verifiability of fossil fuel transactions also creates opportunities for government oversight, which could be expanded in the interests of supply-side climate governance. These properties of fossil fuel flows and their social context suggest that fossil fuel production figures would be a more reliable basis for climate accountability and governance than fossil fuel reserves.

Nevertheless, there are some limitations with using mere volumetric figures for climate governance. The energy content of a given quantity of fuels can vary, and it is the energy content that matters from a climate perspective as it affects the carbon intensity of the fuel. A fuller picture of fossil fuel producers' causal role in climate change is therefore attained through fossil fuel production-based carbon-accounting, which in turn relies on measurements of a fuel's energy content. Determining the energy content of fossil fuels (and other "quality" factors), however, requires more sophisticated laboratory testing of shipment samples. Depending on the terms of a given contract, producers may do this testing themselves or contract it out to an independent surveyor, whose quality assessments form the basis of certifications attached to shipments. Testing arrangements provide opportunities for corruption on the supplier's side of the supplier/customer interface. Recently, for example, global coal markets were rocked by the revelation that laboratory tests in Australia by a large testing company were faked over the course of decades to "keep clients happy". ${ }^{15}$ The replicability of laboratory testing suggests that stricter regulation, mandating more frequent and independent testing, could reduce this risk. Still, there is likely to be a trade-off between using a rougher proxy for climate contribution that is more reliable (volumes of each fossil fuel) and a closer proxy for climate contribution that is more amenable to manipulation and gaming (carbon embodied in fossil fuel production).

Given the broad suitability of fossil fuel production volume data for climate accountability and governance, it is worth considering the potential for the collection of such data to be scaled globally. Until recently, efforts to aggregate production data have largely been confined to the national level, as many states have come to see fossil fuel production both as a source of national wealth and a matter of national security. Nonetheless, this interplay of market and security logics in oil production has also led to the formation of international

\footnotetext{
${ }^{15}$ Liam Walsh, "'It's unethical': Why I altered coal data results", Australian Financial Review, 15 January 2021, <https://www.afr.com/companies/mining/it-s-unethical-why-i-altered-coal-data-results20210113-p56tvd>.
} 
institutions. The International Energy Agency (which largely formalised the rich-country "oil buyers' club" following the oil shocks of the 1970s), and more recent initiatives such as the Joint Organisations Data Initiative (JODI) have sought to make oil and gas conform to economists' models of markets, and states' desire for security of oil supply. JODI is a joint initiative of various international bodies that explicitly aims to reduce the "data uncertainty" that contributes to volatility in energy markets. ${ }^{16}$ However, doubts remain about the success of this initiative. Moreover, JODI's interests in transparency are conceived narrowly in terms of market stabilisation and efficiency, underscoring the wider concern mentioned earlier: that the MRV of fossil fuel production remains dominated by elite actors with a relatively narrow set of commercial interests. A nascent collaborative initiative between three NGOs challenges this paradigm (FFNPTI 2020). The initiative aims to develop a Global Registry of Fossil Fuels, which involves monitoring and reporting production data from every field in every country, with a view to informing supply-side climate governance efforts. ${ }^{17}$ The results of this ongoing initiative will shed further light on the feasibility of fossil fuel production-based accountability frameworks in international climate governance.

\section{Fossil fuel infrastructure}

The third possible object of supply-side climate governance is fossil fuel production projects and infrastructure (hereafter "infrastructure" for simplicity). Fossil fuel infrastructure has various features that are conducive to MRV that yields high quality information.

The principal benefit of fossil fuel infrastructure is that the infrastructure itself, and the practices surrounding it, are transparent to a wide range of observers, including civil society actors. Fossil fuel infrastructure under construction and in operation typically has a large physical footprint, meaning it is easily observable by third parties on the ground and via satellite imagery. Detection by such third parties, moreover, does not require complex measurement procedures or any specialist training and equipment. Further, because fossil fuel infrastructure has a large physical footprint and requires substantial, upfront investment in fixed assets, project proponents typically must undertake various activities before the project becomes operational. These may include making announcements to investors, obtaining government approvals and licences, and negotiating with local stakeholders. The physical footprint of fossil fuel infrastructure often provokes local forms of resistance grounded in concerns about competing land and water usages and local pollution risks, which gives a wide-range of groups - well beyond typical climate activistsa stake in infrastructure approval processes (Cheon and Urpelainen 2018). Because of the salience and observability of infrastructure-related processes to such a wide range of third parties, producer countries can be held to account for fuelling climate change via civil society accountability channels more readily than is the case with other potential objects of supply-side (and carbon-based) climate governance. ${ }^{18}$

\footnotetext{
${ }^{16}$ JODI FAQs, $<$ https://www.jodidata.org/about-jodi/faqs.aspx>.

${ }^{17}$ Forthcoming at $<$ https://fossilfuelregistry.org/>.

${ }^{18}$ The extent to which these activities occur and are observable by third parties is somewhat contextdependent, with fossil fuel infrastructure-related developments typically more easily observable for
} 
These features of fossil fuel infrastructure and its implications for climate governance are well illustrated by the work of the NGO Global Energy Monitor (GEM). GEM is dedicated to providing transparent information about the global energy system, including descriptive data on fossil fuel infrastructure around the globe. ${ }^{19}$ This data is housed and regularly updated on GEM Wiki ${ }^{20}$ - an open, community-built resource featuring interlinked pages covering all aspects of the global energy system, thousands of which are individual "profiles" of fossil fuel projects. ${ }^{21}$ Each profile is a footnoted online fact sheet, providing data on such matters as the project's location, size, capacity (e.g. production capacity of coalmines; throughput capacity of pipelines), developmental status (e.g. "pre-construction", "operating"), ownership and financing. Many profiles also include detailed information about the project's history and about ongoing economic and political developments. GEM Wiki relies primarily on a decentralised crowdsourcing model to provide timely and accurate information about fossil fuel infrastructure. Anyone with internet access can create new articles on the GEM Wiki and edit existing ones, and GEM relies on a network of local volunteer contributors and partner organisations to input the data. The transparency of fossil fuel infrastructure to lay citizens, local activists, journalists and other interested parties means that relevant project developments can be monitored and reported in close to realtime by individuals and organisations with public interest motivations. It is also conducive to accuracy: with such transparent activities, the risk of inaccuracies arising and remaining undetected and uncorrected by other contributors to the site is low. ${ }^{22}$

Finally, fossil fuel infrastructure falls into a small number of categories (oil rigs; LNG terminals etc.) within which the technologies used are relatively standardised across the globe. This makes it easier to detect fossil fuel infrastructure developments and operations, and to aggregate information within each category. This feature is also exploited by GEM: its various "Tracker" projects aggregate the infrastructure data from GEM Wiki into thematic databases and maps of various types of energy infrastructure, allowing GEM to aggregate, visualise, analyse and communicate its data in a user-friendly way. ${ }^{23}$

The main drawback of using fossil fuel infrastructure for climate governance is that the data generated provides only a very rough proxy of a country's contribution to climate change because it does not account for the capacity and output of the projects in question, let alone the embodied carbon. This means that climate governance efforts focused solely on infrastructure could create perverse incentives. For example, limiting the number of new coalmines or petroleum drilling sites would encourage the development of larger sites and the more intense utilisation of existing infrastructure. This suggests the value of a hybrid

\footnotetext{
stock-exchange listed entities and in jurisdictions with more stringent regulatory requirements (see Heller and Mihalyi 2019 regarding NOC disclosures).

${ }^{19}$ GEM also tracks public finance flows for coal and the GEM Wiki contains a range of entries on the global energy system that extend beyond fossil fuel infrastructure.

${ }^{20}$ GEM Wiki is a collaboration between GEM and the Center for Media and Democracy.

${ }^{21}$ GEM Wiki (main page), < https://www.gem.wiki/Main Page > accessed 19/5/2021.

${ }^{22}$ Ibid.

${ }^{23}$ See GEM, Projects, $<$ https://globalenergymonitor.org/projects/>.
} 
accountability framework focused on both infrastructure and production - a point to which we return in our concluding discussion. ${ }^{24}$

\section{Concluding discussion}

In closing, we highlight our two key findings and draw some conclusions about the desirable direction of supply-side international climate cooperation. Our paper has contributed to the debate about this issue by evaluating plausible candidate objects of governance-reserves, production and infrastructure - in light of their characteristics and the possibilities for MRV and accountability to which they give rise.

First, we have raised major concerns about anchoring climate governance in a fossil fuel reserve-based accountability framework. The construction of facts about fossil fuel reserves requires extensive expert and values-based judgements by professionals who are accountable to firms and professional bodies with histories and interests entwined with market logics of extraction for profit. The chequered history of carbon-based MRV, accounting and trading suggests this combination of features poses a high risk of manipulation and gaming by profit-maximising firms. A further problem arises from the fact that climate governance-especially climate laws-inform the very expert judgements that determine reserves figures in the first place.

Though not suitable as an object of governance for the purpose of international climate cooperation, reserves figures, with suitable reforms to harmonise and aggregate the data, could potentially be useful as an additional information source-for example, to provide an indicative historical baseline to inform policy planning; to provide a secondary information source by which to informally gauge progress in decarbonisation efforts; and to inform civil society about the location and size of potential future production sites. There is undoubtedly social value in ongoing efforts to align fossil fuel reserves disclosures with carbon limits (e.g. Carbon Tracker Initiative 2011), but our analysis suggests this value lies mainly in improving the accountability of firms to investors and in enhancing the efficiency and governance of capital markets, rather than in holding states to account for their contribution to climate change. The democratisation of reserve reporting is thus a political project yet to come.

Our second set of findings sheds light on some more promising directions for fossil fuelbased climate governance based on the MRV of fossil fuel production volumes and infrastructure. Fossil fuel production data are less susceptible to manipulation than reserves (and $\mathrm{CO}_{2} \mathrm{e}$ ) figures, and provide a more proximate indication of a state's causal role in

\footnotetext{
${ }^{24}$ A variant of infrastructure accounting that takes into account the infrastructure's capacity could be used for climate governance purposes. A state's capacity to produce and supply the various fossil fuels via relevant infrastructure provides a more proximate measure of its climate contribution than infrastructure per se. However, capacity does not necessarily imply actual production (infrastructure can be under-utilised), so any infrastructure capacity measure would be insufficient for climate governance purposes. Moreover, adopting this unit of account would imply some loss in data transparency, since infrastructure capacity is not directly observable by third parties in the way that a piece of infrastructure itself is observable.
} 
climate change than infrastructure data. However, a drawback is that the activities and transactions that underpin production data are only transparent to actors with relatively narrow commercial interests, meaning governments would need to exercise expanded regulatory oversight. By contrast, fossil fuel infrastructure provides a less proximate indicator of carbon contribution, but is transparent to a wide range of third parties in close to real time. Crucially, infrastructure is transparent and salient to civil society actorsincluding the multiplicity of groups invested in competing land and water uses - which offers the invaluable benefit of mobilising public-spirited agents in the governance effort.

Our analysis points to the virtues of a hybrid fossil fuel-based accountability framework that accounts for infrastructure and production volumes. ${ }^{25}$ Such a framework would lend itself to application in two parallel (or sequential) international climate governance initiatives. The first initiative is a ban on new fossil fuel infrastructure/projects (and infrastructure/project expansions). Such a ban makes principled sense, because adding new fossil fuel infrastructure risks locking-in emissions that would exceed carbon budgets consistent with the Paris climate goals (International Energy Agency 2021; Pfeiffer et al. 2018; Smith et al. 2019; Tong et al. 2019). It would also crystallise a clear and compelling prohibitionary norm, compliance with which can easily be monitored and verified by civil society actors (Green 2018c, 2018a). As noted earlier, this combination of features is conducive to compliance cascades among cooperating states and has the potential to build trust and confidence ahead of more ambitious cooperation, such as a managed and just phase-out of existing infrastructure and/or production volumes (Green 2018c, 2018a). Moreover, the fact that MRV can effectively be outsourced to NGOs like GEM means such a cooperative regime could be established quickly (Green 2018c). The second proposed initiative is a phase-out of existing production. This could be managed through a system of diminishing production quotas, similar to the way the Montreal Protocol manages the production phase-out of ozonepolluting gases. The Powering Past Coal Alliance, the aim of which is a phase-out of coalfired power stations in a Paris Agreement-consistent timeframe, provides something of a template for the two initiatives we envisage (Green 2018c).

Our conclusions are especially pertinent in the light of ongoing NGO efforts to develop a global registry of fossil fuels to anchor nascent supply-side climate governance initiatives. ${ }^{26}$ Thirty years of attempts to precision-manage the climate system via carbon-based accountability frameworks and market mechanisms provide a salutary warning to the would-be architects of fossil fuel-based alternatives. While genuine precision management of the climate is a mirage, its tantalising prospect has inspired a vast, elite-dominated, expert-operated and polluter-captured industry of carbon managers. Fossil fuel-based climate governance anchored in accountability for infrastructure and production offer the potential to break this mould, harnessing the decentralised power of civil society actors to oversee the decline of the fossil fuel era. It won't be precise, but it might just get the job done.

\footnotetext{
${ }^{25}$ Infrastructure capacity data could also be used: see footnote 24 , above.

${ }^{26}$ See footnote 17 , above, and surrounding text.
} 


\section{References}

Allan, Bentley B. 2017. "Producing the Climate: States, Scientists, and the Constitution of Global Governance Objects." International Organization 71: 131-62.

Asheim, G. B. et al. 2019. “The Case for a Supply-Side Climate Treaty.” Science 365(6451): 325-28.

van Asselt, Harro. 2016. "The Role of Non-State Actors in Reviewing Ambition, Implementation, and Compliance under the Paris Agreement." Climate Law 6: 91-108.

Association of Chartered Certified Accountants, and Carbon Tracker Initiative. 2013. Carbon Avoidance? Accounting for the Emissions Hidden in Reserves.

https://www.accaglobal.com/gb/en/technical-activities/technical-resources-

search/2013/october/carbon-avoidance.html.

Barry, Andrew. 2013. Material Politics: Disputes along the Pipeline. Chichester: John Wiley \& Sons.

Bebbington, Jan, Thomas Schneider, Lorna Stevenson, and Alison Fox. 2020. "Fossil Fuel Reserves and Resources Reporting and Unburnable Carbon: Investigating Conflicting Accounts." Critical Perspectives on Accounting 66: 102083.

https://doi.org/10.1016/j.cpa.2019.04.004.

Bell, Ruth Greenspan et al. 2012. Building International Climate Cooperation: Lessons from the Weapons and Trade Regimes for Achieving International Climate Goals. Washington, DC. http://www.wri.org/publication/building-international-climate-cooperation.

Bellassen, Valentin et al. 2015. "Monitoring, Reporting and Verifying Emissions in the Climate Economy." Nature Climate Change 5(4): 319-28.

Bellassen, Valentin, and Nicolas Stephan, eds. 2015. Accounting for Carbon: Monitoring, Reporting and Verifying Emissions in the Climate Economy. Cambridge: Cambridge University Press.

Blum, Mareike. 2020. “The Legitimation of Contested Carbon Markets after Paris - Empirical Insights from Market Stakeholders." Journal of Environmental Policy E Planning 22(2): 226-38.

Camisani-Calzolari, F.A. 2004. “National and International Codes for Reporting Mineral Resources and Reserves: Their Relevance, Future and Comparison." The Journal of The South African Institute of Mining and Metallurgy 104(5): 297-305.

Carbon Tracker Initiative. 2011. Unburnable Carbon - Are the World's Financial Markets Carrying a Carbon Bubble?

Chayes, Abram, and Antonia Handler Chayes. 1991. "Compliance without Enforcement: Sate Behavior under Regulatory Treaties.” Negotiation Journal (July): 311-30.

- - - 1998. The New Sovereignty Compliance with International Regulatory Agreements. Cambridge, MA.: Harvard University Press.

Cheon, Andrew, and Johannes Urpelainen. 2018. Targeting Big Polluters: Understanding Activism Against and the Fossil Fuel Industry.

Collier, Paul, and Anthony J. Venables. 2015. “Closing Coal: Economic and Moral 
Incentives." Oxford Review of Economic Policy 30(3): 492-512.

Davis, Steven J., Glen P. Peters, and Ken Caldeira. 2011. “The Supply Chain of CO2

Emissions." Proceedings of the National Academy of Sciences of the United States of America 108(45): 18554-59.

Dehm, Julia. 2018. “One Tonne of Carbon Dioxide Equivalent (1tCO2e)." In International Law's Objects, eds. Jessie Hohmann and Daniel Joyce. Oxford: Oxford University Press, 305-18.

Falkner, Robert. 2016. "The Paris Agreement and the New Logic of International Climate Politics." International Affairs 92(5): 1107-25.

Finnemore, Martha, and Kathryn Sikkink. 1998. "International Norm Dynamics and Political Change." International Organization 52(4): 887-917.

Fossil Fuel Non-Proliferation Treaty Initiative. 2020. “A Global Registry of Fossil Fuels: Request for Proposals."

Green, Fergus. 2018a. "Anti-Fossil Fuel Norms." Climatic Change 150: 103-16.

- - - . 2018b. Fighting Climate Change with Fossil Fuel Free Zones. Canberra. https://www.tai.org.au/content/fighting-climate-change-fossil-fuel-free-zones.

- - - 2018c. “The Logic of Fossil Fuel Bans.” Nature Climate Change 8: 449-451.

Green, Fergus, and Richard Denniss. 2018. "Cutting with Both Arms of the Scissors: The Economic and Political Case for Restrictive Supply-Side Climate Policies." Climatic Change 150: 73-87.

Gupta, Aarti, and Harro van Asselt. 2019. "Transparency in Multilateral Climate Politics: Furthering (or Distracting from) Accountability?" Regulation and Governance 13: 18-34.

Hale, Thomas. 2016. “'All Hands on Deck': The Paris Agreement and Nonstate Climate Action." Global Environmental Politics 16(3): 12-22.

Harrison, Kathryn. 2015. "International Carbon Trade and Domestic Climate Politics." Global Environmental Politics 15(3): 27-48.

Heller, Patrick R. P., and David Mihalyi. 2019. Massive and Misunderstood: Data-Driven Insights into National Oil Companies.

https://resourcegovernance.org/sites/default/files/documents/massive_and_misunderst ood_data_driven_insights_into_national_oil_companies.pdf.

Huber, Matthew T. 2013. Lifeblood: Oil, Freedom, and the Forces of Capital. Minneapolis: University of Minnesota Press.

International Energy Agency. 2021. Net Zero by 2050: A Roadmap for the Global Energy Sector. Paris. https://www.iea.org/reports/net-zero-by-2050.

Interpol. 2013. Guide to Carbon Trading Crime. Lyon.

Jacobs, Michael. 2016. “High Pressure for Low Emissions: How Civil Society Created the Paris Climate Agreement." Juncture 22(4): 314-23.

Jasanoff, Sheila. 2006. “Technology as a Site and Object of Politics." In The Oxford Handbook of Contextual Political Analysis, eds. Robert E. Goodin and Charles Tilly. Oxford: Oxford 
University Press, 745-64.

Johnston, Alastair Iain. 2001. “Treating International Institutions as Social Environments.” International Studies Quarterly 45: 487-515.

Karlsson-Vinkhuyzen, Sylvia I. et al. 2018. "Entry into Force and Then? The Paris Agreement and State Accountability." Climate Policy 18(5): 593-99.

Keohane, Robert O, and Michael Oppenheimer. 2016. "Paris: Beyond the Climate Dead End through Pledge and Review?" Politics and Governance 4(3): 142-51.

Kerr, Suzi, and Vicki Duscha. 2014. "Going to the Source: Using an Upstream Point of Regulation for Energy in a National Chinese Emissions Trading System." Energy and Environment 25(3-4): 593-611.

Kuch, Declan. 2015. The Rise and Fall of Carbon Emissions Trading. Basingstoke, UK: Palgrave Macmillan.

Lövbrand, Eva, and Johannes Stripple. 2011. "Making Climate Change Governable: Accounting for Carbon as Sinks, Credits and Personal Budgets." Critical Policy Studies 5(2): 187-200.

MacKenzie, Donald. 2009. "Making Things the Same: Gases, Emission Rights and the Politics of Carbon Markets." Accounting, Organizations and Society 34(3-4): 440-55.

Manley, David, and Patrick R. P. Heller. 2021. Risky Bet: National Oil Companies in the Energy Transition. https://resourcegovernance.org/analysis-tools/publications/risky-betnational-oil-companies-energy-transition.

Martin, Peter, and Reece Walters. 2013. "Fraud Risk and the Visibility of Carbon." International Journal for Crime, Justice and Social Democracy 2(2): 27-42.

Mason, Michael. 2005. The New Accountability: Environmental Responsibility Across Borders. London: Earthscan.

- - . 2008. "Transparency for Whom? Information Disclosure and Power in Global Environmental Governance." Global Environmental Change 8(2): 8-13.

Mitchell, Timothy. 2011. Carbon Democracy: Political Power in the Age of Oil. London: Verso.

Newell, Peter. 2008. "Civil Society, Corporate Accountability and the Politics of Climate Change." Global Environmental Politics 8(3): 122-53.

Newell, Peter, and Andrew Simms. 2020. “Towards a Fossil Fuel Non-Proliferation Treaty." Climate Policy 20(8): 1043-54.

Nyborg, Karine et al. 2016. "Social Norms as Solutions." Science 354(6308): 42-43.

Paterson, Matthew, and Peter Newell. 2010. Climate Capitalism: Global Warming and the Transformation of the Global Economy. Cambridge, UK: Cambridge University Press.

Pearse, Rebecca. 2018. Pricing Carbon in Australia: Contestation, the State and Market Failure. Routledge.

Pearse, Rebecca, and Stefen Böhm. 2014. “Ten Reasons Why Carbon Markets Will Not Bring about Radical Emissions Reduction." Carbon Management 5(4): 325-37.

Pfeiffer, Alexander, Cameron Hepburn, Adrien Vogt-Schilb, and Ben Caldecott. 2018. 
"Committed Emissions from Existing and Planned Power Plants and Asset Stranding Required to Meet the Paris Agreement." Environmental Research Letters 13(5): n. 054019.

Piggot, Georgia, Peter Erickson, Harro van Asselt, and Michael Lazarus. 2018. "Swimming Upstream: Addressing Fossil Fuel Supply under the UNFCCC." Climate Policy 18(9):

1189-1202.

Schneider, Lambert. 2009. "Assessing the Additionality of CDM Projects: Practical

Experiences and Lessons Learned." Climate Policy 9(January 2013): 242-54.

- - - 2011. "Perverse Incentives under the CDM: An Evaluation of HFC-23 Destruction Projects." Climate Policy 11(January 2013): 851-64.

Shishlov, Igor, Romain Morel, and Valentin Bellassen. 2016. "Compliance of the Parties to the Kyoto Protocol in the First Commitment Period." Climate Policy 16(6): 768-82.

http://dx.doi.org/10.1080/14693062.2016.1164658.

Smith, Christopher J. et al. 2019. "Current Fossil Fuel Infrastructure Does Not yet Commit Us to $1.5^{\circ} \mathrm{C}$ Warming." Nature Communications 10(1): 1-10. http://dx.doi.org/10.1038/s41467-018-07999-w.

Steininger, Karl W. et al. 2016. "Multiple Carbon Accounting to Support Just and Effective Climate Policies." Nature Climate Change 6(1): 35-41.

Stevenson, Hayley. 2021. "Reforming Global Climate Governance in an Age of Bullshit." Globalizations 18(1): 86-102.

Streck, Charlotte. 2020. “The Mirage of Madrid: Elusive Ambition on the Horizon.” Climate Policy 20(2): 143-48.

Stripple, Johannes, and Eva Lövbrand. 2010. "Carbon Market Governance beyond the Public-Private Divide." In Global Climate Governance Beyond 2012: Architecture, Agency and Adaptation, eds. Frank Biermann, Philipp Pattberg, and Fariborz Zelli. Cambridge: Cambridge University Press.

Taylor, Bernard. 2006. "Shell Shock: Why Do Good Companies Do Bad Things?" Corporate Governance: An International Review 14(3): 181-93.

Timmermans, Stefan, and Steven Epstein. 2010. “A World of Standards but Not a Standard World: Toward a Sociology of Standards and Standardization." Annual Review of Sociology 36: 69-89.

Tong, Dan et al. 2019. “Committed Emissions from Existing Energy Infrastructure Jeopardize $1.5^{\circ} \mathrm{C}$ Climate Target." Nature 572(7769): 373-77.

Tordo, Silvana, Brandon S. Tracy, and Noora Arfaa. 2011. National Oil Companies and Value Creation. Washington, DC.

Victor, David G. 2001. The Collapse of the Kyoto Protocol and the Struggle to Slow Global Warming. Princeton, N.J.: Princeton University Press.

- - - 2011. Global Warming Gridlock: Creating More Effective Strategies for Protecting the Planet. Cambridge: Cambridge University Press.

Weikmans, Romain, Harro van Asselt, and J. Timmons Roberts. 2020. “Transparency Requirements under the Paris Agreement and Their (Un)Likely Impact on 
Strengthening the Ambition of Nationally Determined Contributions (NDCs)." Climate Policy 20(4): 511-26.

Weszkalnys, Gisa. 2015. “Geology, Potentiality, Speculation: On the Indeterminacy of First Oil30." Cultural Anthropology 30(4): 611-39. 